\title{
New York mark-ups on petroleum products*
}

\author{
Szymon Wlazlowski ${ }^{\ddagger}$, Jane Binner ${ }^{\ddagger \dagger}$, Monica Giulietti ${ }^{\ddagger}$, Nathan Joseph ${ }^{\ddagger}$ \\ Birger Nilsson ${ }^{\S}$
}

This version: August 6, 2007

\begin{abstract}
This paper analyzes rigidities in the behavior of mark-up on petroleum products in the New York area using a new set of high-frequency data. We use a methodology that accounts both for deterministic and stochastic nature of petrol prices. The results indicate that the adjustment to the long run equilibrium mark-up is non-linear with adjustment speeds that are equal across regimes for two out of the three series analyzed. For one of the series the adjustment is beneficial for end consumers as we find that prices fall faster than they rise.
\end{abstract}

JEL Classification: C52, D4, L11, Q40.

Keywords: Asymmetric Price Transmission, Petroleum, SETAR model, Regime Switching model

\section{Introduction}

This paper analyzes the non-linearities in the behavior of cost items in the local market for petroleum in the New York area. A SETAR model of the class proposed by Tong (1978) and Tong \& Lim (1980) is used to analyze the reversion of the mark-up on costs to its long run equilibrium level. This approach allows us to check for the responses of petrol prices to upstream price changes and verify the old claim that petrol prices "rise faster than they fall".

\footnotetext{
*The authors wish to thank to Michael J. Dueker, Assistant Vice President, Federal Reserve Bank of St. Louis for helpful comments.

${ }^{\dagger}$ Corresponding author: E-mail: j.m.binner@aston.ac.uk, tel: 0044(0)121 2043036.

¥Aston Business School, Aston Triangle, Birmingham B4 7ET, UK

$\S$ Department of Economics, Lund University, SE-220 07 Lund, Sweden
} 
Karrenbrock (1991) presents an impressive list of excerpts from newspapers quoting drivers and officials who are outraged by the behavior of petrol companies.

Non-linearities in the speed of adjustment to the upstream prices have attracted significant attention, both from applied researchers and from governmental agencies. Since non-linearities in transmission might involve welfare transfer from agents downstream / end users to companies upstream, the public agencies have vigorously pursued this issue. This can be seen in a variety of reports associated with various agencies (see, e.g., reports by General Accounting Office (1993) for US, Competition Bureau (1997) for Canada, and Monopolies and Mergers Commission (1990) and Office of Fair Trading (1998) for the UK.

This phenomenon is more formally referred to as "asymmetric price transmission". The graphic term usually used in this context is "rockets and feathers". This term is coined by Bacon (1991) to describe fast increases in downstream prices following upstream increases - rockets launched, and slow decreases following upstream price decreases - feathers falling. The difference between symmetric and asymmetric price transmissions is illustrated in the lower panel in Figure 1.

The existence of asymmetric price transmission implies that by postponing lowering prices, agents artificially increase their margins causing the above-mentioned welfare transfer. This usually forms the most typical motivation for formal research as it might result from tacit or even formal collusion or serious problems with the degree of competition (see Godby, Lintner, Stengos \& Wandschneider (2000)).

Previous studies in the area have several common shortcomings. Firstly, as pointed out by Frey \& Manera (2005), researchers use aggregated petrol prices from a variety of sources, which in turn gives rise to substantial inconsistencies in empirical results. ${ }^{1}$ Secondly, the testing framework used implies that asymmetric price transmission is analyzed with respect to changes in disequilibrium, instead of overall profitability (see section 4.3 for a more formal discussion). Thirdly, no formal tests for non-linearity are performed, with the exceptions of Frey \& Manera (2005) and Godby et al. (2000). Finally, although von Cramon-Taubadel \& Mayer (2001) show that structural changes in the relationship between upstream and downstream prices can be mistaken for the presence of asymmetric price transmission, except for Reilly \& Witt (1998), previous studies do not analyze the stability of the pricing relations. 
Our study employs a novel approach to examine the problem of asymmetries in petrol prices. Firstly, rather than focusing on the behavior of downstream prices, we focus on the behavior of mark-ups on costs. That is, we focus on the residual portion of the downstream (retail) petroleum prices, not coming from the upstream wholesale stage. This allows us to test for the presence of asymmetric price transmission and also to get some insights into the behavior of adjustments of mark-ups on costs towards their long-run equilibrium level.

Secondly, the data employed offers significant improvement over the previous studies as: (i) it is constrained to only one geographically distinct market (greater New York metropolitan area); (ii) instead of using product aggregates, it covers three distinct kinds of petrol (regular, midgrade and premium unleaded petrol); (iii) prices are quoted at a particular point in time, thus representing the true market outcome, rather than an average over days or weeks; (iv) it focuses on one transmission stage only (from New York harbor warehouses to New York filling stations), which is more likely to result in a stable pricing relationship. As demonstrated by Geweke (1978) aggregation over time can create a type of omitted variables bias resulting from insufficient lag structure and can result in finding asymmetries in symmetric processes (see Bachmeier \& Griffin (2003)). Our results show that the adjustment to the long run equilibrium mark-up is non-linear and the speed of adjustment across regimes is similar in most cases in both deterministic and stochastic switch cases. The price adjustment seems to benefit suppliers rather than end consumers in most cases.

The structure of the paper is as follows: section 2 presents the motivation for the research. Section 3 summarizes the framework for testing for asymmetric price transmission. Section 4 presents an overview of data. Section 5 presents the results of the empirical non-linear analysis. A brief summary and description of further research follows.

\section{Motivation}

\section{$2.1 \quad$ Focus}

Most of the research into pricing in petroleum markets has focused on the "rockets and feathers" phenomena (see section 2.2). The behavior of other costs is completely excluded 
from the analysis and profit margins are estimated indirectly, through an analysis of market

disequilibria (Abdulai (2002)). ${ }^{2}$ Our approach has its virtues in that it allows us to directly address the question as to whether downstream consumers enjoy upstream price decreases as quickly as they have to suffer upstream price increases. To be very specific about our results and to avoid some of the problems noted by Frey \& Manera (2005), we focus only on one element of the market. Thus our approach allows us to examine the behavior of residual costs. Focusing on this portion of the price allows us to examine:

- whether there exists asymmetric price transmission in that the mark-up portion of the price increases faster than it decreases, and

- the nature of agents behavior by analyzing changes in the margins earned.

\subsection{Overview of Previous Research}

In perhaps the first study for the US market, Karrenbrock (1991) employed monthly data for 1983-1990 to study the empirical relationship between wholesale and retail petrol prices by regressing downstream price changes on positive and negative upstream prices (but disregarding cointegration issues). Both prices used are reduced by the sum of the federal petrol tax and an average of the 50 states petrol taxes. He finds that the length of time in which a wholesale price increase is fully reflected in the retail petrol price is the same as that of a wholesale decrease for premium and unleaded regular petrol. The null hypothesis of symmetric transmission is not rejected. Karrenbrock (1991) concludes that, contrary to a commonly held belief drivers do benefit from wholesale petrol price decreases, as these are passed along as fully and quickly as wholesale price increases.

Shin (1992) applies the model by Karrenbrock (1991) to crude-wholesale price transmission, using monthly data over the period 1986-1992. He estimates a model with only contemporaneous price effects (i.e. regressed upstream changes on downstream increases and decreases. His results show that crude oil price variations have a symmetric impact on the wholesale market).

Another study concerned with asymmetric transmission in the USA is by Borenstein, Cameron \& Gilbert (1997). For their analysis of price transmission between 1986 and 1992 
they use weekly data on prices at different processing levels. After testing for the homogeneity of the contemporaneous change in the upstream price in all of the transmissions they adopt two-stage least squares estimation. Using the framework provided by the Error Correction Model (ECM), they confirm that retail petrol prices respond more quickly to increases than to decreases in crude oil prices. The adjustment takes approximately 8 weeks in the case of decreases in crude oil prices but only 4 weeks in the case of increases in prices of crude oil.

Balke, Brown \& Yücel (1998) extend the work of Borenstein et al. (1997) using a different model specification. They use data from January 1987 through August 1996 on weekly prices of West Texas Intermediate crude, spot prices for unleaded petrol in the New York harbor, wholesale price of petrol and retail prices of self-service unleaded motor spirit with and without taxes. They establish that upstream prices Granger-cause downstream prices at all stages of the distribution chain. The results of their bivariate vector autoregressive models for each pair of series suggest that with one exception (relationship between spot price of crude oil and wholesale spot price of petrol) price shocks originate upstream and are transmitted downstream. The null of symmetry in transmission is rejected in nine out of ten pairs of price series, with the exception of spot retail transmission.

Godby et al. (2000) use weekly data on self-service regular and premium petrol net of taxes and Edmonton par and Montreal Brent crude oil cost for the period January 1990 to December 1996 for 13 Canadian cities. They apply the bootstrapping procedure proposed by Hansen (1996) to test the null hypothesis of a linear formulation against an asymmetric alternative. Only weak evidence of asymmetry is found. The finding is attributed to the frequency of the data used and to the fact that previous studies use aggregate data on prices from distinct regions.

Bachmeier \& Griffin (2003) revisited data used by Borenstein et al. (1997) to compare their results with those obtained using higher frequency data and larger sample (from February 1985 to November 1998). Their results indicate that daily retail prices adjust almost instantaneously and symmetrically to crude oil price changes.

The research by Eckert (2002) is inspired by the cyclical behavior of downstream prices in Ontario, Canada, which might be mistaken for asymmetries. The testing procedure follows Borenstein et al. (1997), with the use of quarterly dummies and three level shifts to account 
for the first Gulf war. In this model, the null of symmetry in transmission is rejected. After ascertaining that asymmetric transmission is present, the more sophisticated model of price cycles is estimated with the use of a combined Probit-OLS procedure. The results are interpreted as proof that changes in both regimes are dependent on upstream prices and are decreasing functions of margins. Eckert (2002) concludes that asymmetries between different portions of the price cycle described by Maskin \& Tirole (1988) can be mistaken for asymmetries in price responses.

Radchenko (2005) analyzes the link between oil price volatility and the asymmetric response of petroleum prices to oil price variations. Weekly data from March 1991 to February 2003 are used to compute the impulse response functions to crude price increases and decreases. The results show that the response of retail prices to changes in crude oil prices is asymmetric. Radchenko \& Tsurumi (2005) apply a similar model to geographically aggregated (region-wide) weekly data from March 1991 to February 2003 again to find welfaredecreasing asymmetries in price transmission.

More recently, Noel (2007) uses Markov-switching regression to estimate the prevalence of three regimes he identified - cost-based pricing, sticky pricing, and sharp asymmetric retail price cycles. While focused on a cross-country setting, this paper represents an interesting attempt to use purely stochastic methods to explain what triggers asymmetric patterns in pricing behavior.

We build upon the existing literature, improving it in terms of data available (higher frequency and lower geographical aggregation) and applied model (we corroborate the traditional deterministic models with a stochastic switching model). As such, we provide the first available evidence on whether or not the "rockets and feathers" holds in the New York area at present. 


\section{Traditional models of mark-up behavior}

\subsection{Relationship between prices}

In order to analyze asymmetries in petroleum pricing it is necessary to explain the responses of downstream prices to upstream changes. One model to capture changes in the downstream prices is:

$$
y_{t}=y_{t-1}+\gamma_{0}\left(y_{t-1}^{*}-y_{t-1}\right)+\nu_{t}
$$

where $y_{t}^{*}$ is the equilibrium downstream price, $y_{t}$ is the actual downstream price and $\gamma_{0}$ is adjustment speed (a shock would linger forever if $\gamma_{0}=0$ and would be eliminated at once if $\left.\gamma_{0}=1\right)$. The equilibrium price $\left(y_{t}^{*}\right)$ is established based on the long-run relationship between upstream and downstream prices, i.e.:

$$
y_{t}^{*}=\beta_{0}+\beta_{1} x_{t}+\epsilon_{t}
$$

where $x_{t}$ is the upstream price, $\beta_{0}$ is the constant (could be understood in terms of fixed costs of transmission), $\beta_{1}$ is the proportion of downstream costs passed through upstream and $\epsilon_{t}$ represents shocks to the system.

The approach proposed by Engle \& Granger (1987) combines the two elements discussed above and can be used to estimate the adjustment of downstream prices:

$$
\Delta \hat{\epsilon}_{t}=\gamma_{0} \hat{\epsilon}_{t-1}+\sum_{i=1}^{m} \gamma_{i} \Delta \hat{\epsilon}_{t-i}+\nu_{t}
$$

where $\hat{\epsilon}_{t}$ are OLS residuals from level price equation, $\gamma_{0}$ is the speed of adjustment, and $\sum_{i=1}^{m} \gamma_{i} \Delta \hat{\epsilon}_{t-i}$ is the lagged left-hand side variable.

In this two-stage cointegration analysis, the existence of the long-run relationship between prices is tested under $H_{0}: \gamma_{0}<0$. On the basis of that, it is assumed that upstream and downstream prices are cointegrated, and that the residuals proxy the disequilibria to the system. As pointed out by Abdulai (2002), this forms the basis for testing for asymmetric price transmission. 


\subsection{Non-linear Modeling}

It is assumed that the residuals $\hat{\epsilon}_{t}$ proxy the changes to margins earned (see Frey \& Manera (2005) for an overview of non-linear models of asymmetric price transmission). Based on the analysis of those residuals, researchers look for the presence of asymmetric price transmission.

The analysis of asymmetric price transmission focuses on non-linear (piece-wise linear) models of the threshold class first proposed by Tong (1978) and Tong \& Lim (1980). The idea is that (because of menu costs, transaction costs, search costs, etc.) pricing decisions follow one of two possible regimes. While this might be an oversimplification, it allows us to capture the basic non-linearities present in the data.

In this setting, the piece-wise linear model can capture the differences between regimes and establish the presence of asymmetric price transmission. This piecewise linear extension of eq. 3 into two different regimes can be represented by:

$$
\Delta \hat{\epsilon}_{t}=\left\{\begin{array}{l}
\gamma_{0}^{(L)} \hat{\epsilon}_{t-1}+\sum_{i=1}^{m} \gamma_{i}^{(L)} \Delta \hat{\epsilon}_{t-i}+\nu_{t}^{(L)} \text { when } \hat{\epsilon}_{t-d}<r \\
\gamma_{0}^{(H)} \hat{\epsilon}_{t-1}+\sum_{i=1}^{m} \gamma_{i}^{(H)} \Delta \hat{\epsilon}_{t-i}+\nu_{t}^{(H)} \text { when } \hat{\epsilon}_{t-d} \geq r
\end{array}\right.
$$

where $\hat{\epsilon}_{t-d}$ is the self-exciting threshold variable with delay set to $d$. The estimation of threshold parameters and slope variables should be done via a grid search (as advised by Hansen (1997) and Tsay (1998)), i.e. over all optimum values of thresholds $\bar{r}$ and lags $\bar{d}$ so as to minimize the sum of the squared residuals from the fitted models, i.e.:

$$
(\bar{r}, \bar{d})=\underset{\bar{r}, \bar{d}}{\operatorname{argmin}} R S S(\bar{r}, \bar{d})
$$

To avoid trivial results, the extreme values of threshold variables should be excluded from the estimation (see Hansen (1997)).

The last remaining task is to test for the presence of piecewise linear adjustment, i.e. for the presence of asymmetric price transmission. This boils down to testing of $H_{0}:\left(\gamma_{i}^{(L)}=\right.$ $\left.\gamma_{i}^{(H)}, \forall_{i}\right)$, i.e. of no significant difference between the parameters in each of the regimes. This could be done using Wald test in the following form:

$$
F_{12}=n * \frac{R S S_{1}-R S S_{2}}{R S S_{2}}
$$


where $n$ is the sample size, $R S S_{1}$ and $R S S_{2}$ are from eq. 3 and 4 , respectively.

As noted by Hansen (1996), since the threshold parameter is not identified under the null, the asymptotic distribution of $F_{12}$ is not standard, but can be bootstrapped by the following procedure. Denote $u_{t}^{*} \sim^{\text {iid }} N(0 ; I)$, (i) draw the vector of $u_{t}^{*}$, (ii) regress $u_{t}^{*}$ on right hand side variables from eq. 3 and obtain the residual variance $R S S_{1}^{*}$, (iii) regress $u_{t}^{*}$ on right hand side variables from eq. 4, obtain residual variance $R S S_{2}^{*}$, (iv) calculate eq. 6, repeat (i)-(iv) a large number of times and use sample quantiles as the critical values.

In the setting described above, the process of eliminating the disequilibria determine the adjustment of downstream prices to upstream price changes. In a non-linear framework, those disequilibria are eliminated in regimes $(L)$ and $(H)$ with different speeds which gives rise to non-linearities. One of such nonlinearities which attracts the public attention (i.e. when prices rise faster than they fall) occurs when positive disequilibria (corresponding to times of decreasing upstream prices) are eliminated at a slower pace than negative disequilibria (corresponding to times of increasing upstream prices).

The modeling of mark-up on costs involves essentially the same traditional models described above. The only difference is that it is assumed that the upstream costs are fully passed on downstream $\left(\beta_{1}=1\right.$ which, given the vertical span between tiers, is a viable assumption) so that the residuals between upstream and downstream prices (mark-up) are comprised of retailers' margins and other downstream costs. As such, eq. 2 becomes:

$$
y_{t}=\pi_{t}+x_{t}+\nu_{t}
$$

where $\pi_{t}$ represents the mark-up, and the problem of adjustment of downstream prices to upstream price changes (i.e. elimination of disequilibria) is simplified to the problem of adjustment of $\pi_{t}$ to its long run level:

$$
\pi_{t}=\pi_{t-1}+\gamma_{0}\left(\pi_{t-1}^{*}-\pi_{t-1}\right)+\nu_{t}
$$

where $\pi_{t}^{*}=\alpha+\epsilon_{t}$, since it is assumed that mark-up on costs is constant and does not depend on upstream prices. Now the analysis of disequilibria in mark-up $\hat{\epsilon}_{t}$ can be done using the same procedure discussed with respect to equations 3 and 4 . 


\section{Petroleum Product Prices}

\subsection{Overview of the Data}

Weekly retail data from June 2000 until December 2005 are obtained from the U.S. Energy Information Agency. The data used represent the entire population of prices provided by the agency. The series represent prices charged for three grades of petroleum products in approximately 900 retail outlets. The prices are published by 5 p.m. Monday, except for the bank holidays, when the data are released on Tuesday (but still represent Monday's price). The reported price includes all taxes and is the price paid by a consumer at the pump as of 8 a.m. Monday.

Daily spot prices for the New York area from June 2000 until December 2005 come from the U.S. Energy Information Agency. These series include wholesale prices quoted on the day when retail prices are collected. When data on wholesale prices for a given day is not available, the previous day's prices are used.

The series analyzed include:

- downstream prices: ${ }^{3}$

$-y_{t}^{1}-\mathrm{NYC}$ / harbor regular all formulations / reformulated retail petrol prices net of all taxes;

$-y_{t}^{2}-\mathrm{NYC}$ / harbor midgrade all formulations / reformulated retail petrol prices net of all taxes;

$-y_{t}^{3}-\mathrm{NYC} /$ harbor premium all formulations / reformulated retail petrol prices net of all taxes.

- $x_{t}$ - upstream prices - New York harbor reformulated regular petrol.

Figure 2 presents the evolution of the retail and wholesale prices over the sample period.

The New York market suits the purposes of the analysis as:

- the New York metropolitan area constitutes the economic hub on the East Coast;

- the bulk of trade in wholesale petrol takes place in that area (with NY harbor prices being benchmark for the entire East Coast). 
The use of spot regular petroleum prices as a proxy for upstream prices is justified as the regular petroleum is the most popular variety and as such forms the basis most retailers use to price premium and midgrade. The mixing is done with the help of additives and enhancements which increase octane index and help to differentiate petroleum products and create company-specific fuels, such as Formula, Silver Eagle, etc. RFA (2006). As seen in Figure 3, costs of wholesale petrol constitutes the main component of downstream prices. The differences between upstream prices result mainly from costs of additives and enhancements which are constant over time (this is confirmed by the analysis of product spreads, which do not change by more than 3-5 cents over the sample period).

\subsection{Data Analysis}

Before moving to the application of non-linear models, the series are checked for the presence of unit roots, direction of causality and identification of the cointegration vector. The price series analyzed are not subjected to logarithmic transformation. Borenstein et al. (1997) pointed out that using logarithms implies that wholesale-retail margin increases with the upstream price. As an alternative he proposed using the raw data, which implies constant nominal margins in the level equation. Borenstein et al. (1997, p. 312) claim that for short samples with moderate inflation this assumption is justifiable.

The direction of causality is tested using the Granger test. Table 1 presents the results indicating that upstream prices drive downstream prices. Thus, the null hypothesis that the history of downstream prices cannot be used to explain upstream prices is not-rejected, while the reverse is rejected.

The series are also tested for the presence of unit roots using the standard ADF. Table 2 presents the test statistics confirming that the series are integrated of order one. ${ }^{4}$

The existence of a long-run equilibrium relationship between prices is tested using the Phillips \& Ouliaris (1990) test with truncation parameter set to 2. According to Phillips \& Ouliaris (1990, p. 165) this test should have better power than ADF and PP tests, at least in larger samples. As shown in Table 3, the null of no cointegration is rejected for all price pairs. ${ }^{5}$ The notion of upstream and downstream prices being related is supported in some of 
the earlier studies of US markets (see Karrenbrock (1991); Duffy-Deno (1996); Balke et al. (1998); Energy Information Agency (1999); Borenstein et al. (1997) and Bachmeier \& Griffin $(2003))$.

After ascertaining that the series are cointegrated, eq. 2 is estimated for all series. Table 4 presents the results.

The results of the estimation indicate a good fit, as indicated by the values of the $\beta_{1}$ coefficients. The $\beta_{0}$ coefficients should be thought of in terms of constant mark-up, most likely used to cover constant costs of product processing and distribution.

As the last step, we investigate the stability of the relationship given by eq. 10 using the CUSUM test. The results indicate that the long-run equilibrium level of mark-up proxied by $\alpha^{(j)}$ is fairly stable over the sample size at 5\%. Also the empirical fluctuation test, applied in the OLS-CUSUM and recursive versions, supported the null of stable parameters. This finding is important, as von Cramon-Taubadel \& Mayer (2001) shows that the SETAR models tend to mis-identify structural breaks as the signs of asymmetries.

\subsection{Mark-up on petroleum products}

We analyze the long-run mark-up on costs at a given transmission level, calculated as a difference between upstream and downstream prices. This approach allows us to re-state the research question - instead of asking what disequilibria trigger non-linearities, we analyze what levels of profitability trigger different market responses. While both approaches are equivalent in economic terms (assuming constant long-run profitability), our approach is more intuitive and yields readily understandable results.

The proxies for the mark-up on costs on each product are calculated as:

$$
\hat{\pi}_{t}^{(j)}=y_{t}^{(j)}-x_{t}
$$

Figure 4 presents the mark-up earned on regular, midgrade and premium petroleum products.

To analyze the long-run equilibrium mark-up (equal to $\alpha$ ), the following equation is estimated:

$$
\hat{\pi}_{t}^{(j)}=\alpha^{(j)}+\epsilon_{t}^{(j)}
$$


for each of the series (i.e., for $j=1,2,3$ ). This equation assumes the markups to be constant and equal to the difference between upstream and downstream prices, which given the results of OLS estimation and stability of the pricing relationship is a valid assumption. Table 5 present the results. The results indicate varying profitability of distribution of the each product, with the highest quality product receiving the highest mark-up.

\section{Non-linearities in mark-ups}

Residuals from eq. 10 are used to establish the reversion process for the mark-up proxies. The dynamics are established by maximizing the AIC with the initial lags $(m)$ set to 3 months. ${ }^{6}$ Table 6 presents the results of the estimation of equation eq. 3 . The results indicate fast adjustment (almost a quarter of disequilibrium is eliminated each period) and similar dynamics as indicated by the lag structure.

As a next step, we estimate eq. 3 and eq. 4 for all three series so as to assess the speed of adjustment of mark-ups to their long-run values. Table 7 summarizes results for the three models estimated. ${ }^{7}$

Table 8 presents the results of estimation of eq. 4 for each of the series.

The results show that non-linearities in the pricing behavior do exist, as indicated by the significant values of $F_{12}$ statistics. However, the nature of non-linearities is interesting in a number of ways. Results reported in Table 8 indicate that the immediate speeds of adjustment (coefficients on $\hat{\epsilon}_{t-1}$ ) are:

- similar for regular and midgrade petroleum;

- much higher for regime $H$ in the case of premium petrol.

The above results are confirmed by the $\mathrm{F}$ tests. In the first case, the F-test fails to reject null hypothesis of $H_{0}: \gamma_{0}^{(j, L)}=\gamma_{0}^{(j, H)}$ for $j=1$ (regular petroleum) and $j=2$ (midgrade) with p-values equal to 0.5266 and 0.9717 respectively. In the second case, the F-test rejected the null of equal speeds of adjustment with p-value of 0.0017 .

In order to further corroborate the results, the model is also estimated in a stochastic framework. The results are not significantly different from the ones reported. Appendix A 
presents the details.

Figure 5 presents the series analyzed (where solid circles correspond to $H$ regime). The trend visible is that mark-up reverts to its long-run level faster when the disequilibrium is large and positive (so that the downstream prices are above their long-run levels).

Figure 5 also shows that fast-adjustment observations (those from the $H$ regime) cluster around dates when tax rates increase (marked as solid squares) but not with decreases in taxes (triangles). This is puzzling as the taxes should be fully passed on to the customers. Table 9 presents the percentage of observations falling into regime $H$ within $\pm k$ weeks of the date when taxes were increased. Again, the share of observations is double that predicted under the assumption of uniform distribution of regime change $(2 * k / 54)$.

\section{Summary and Conclusions}

The relationship between upstream and downstream prices of petroleum products in the New York area and the behavior of mark-up on costs are analyzed using the cointegration framework and SETAR(2) model. The results indicate that:

- the adjustment of mark-ups to their long run equilibrium level is non-linear in the sense that two distinct regimes can be found in the revision process;

- the differences between the speeds of adjustments are greater for products with thin mark-ups and the periods of faster adjustments are less frequent than those of slow adjustment;

- a graphical analysis of the results suggests that the change of adjustment regimes is more likely to happen shortly before or after increases in taxation.

The results are obtained using disaggregated data on prices of three distinct kinds of petrol (regular, midgrade and premium unleaded petrol), constrained to only one geographically distinct market and one transmission stage (wholesale to retail). This represents a significant innovation with respect to existing literature, as other researchers use heavily aggregated data. The results in this paper are similar to those obtained by Bachmeier \& Griffin (2003) who also used disaggregated data. The results indicates that "rockets and feathers" 
phenomena are not present over the sample period in the NYC. Further studies could extend this approach to other geographic areas and potentially put drivers from other cities at ease.

\section{A Appendix - Stochastic Regime Switching Approach}

As discussed in Frey \& Manera (2005), two different classes of regime switching models (RSM) can be considered depending on the nature of switches between regimes. In the deterministic RSM, e.g. a SETAR model, switches between states occur when a threshold variable reaches a certain value. In the stochastic RSM, switches between states instead occur at random. Often, an underlying discrete state Markov chain governs the switches from one state to another (Hamilton (1989)). In this section, we estimate Markov switching models to investigate the robustness of our results with respect to the class of regime switching models considered.

The econometric specification resembles eq. 4:

$$
\Delta \hat{\epsilon}_{t}=\left\{\begin{array}{l}
\gamma_{0}^{(L)} \hat{\epsilon}_{t-1}+\sum_{i=1}^{m} \gamma_{i}^{(L)} \Delta \hat{\epsilon}_{t-i}+\nu_{t}^{(L)} \text { when } S_{t}=L \\
\gamma_{0}^{(H)} \hat{\epsilon}_{t-1}+\sum_{i=1}^{m} \gamma_{i}^{(H)} \Delta \hat{\epsilon}_{t-i}+\nu_{t}^{(H)} \text { when } S_{t}=H
\end{array}\right.
$$

where $S_{t}$ is the state of the underlying Markov chain prevailing at time $t$. The model is estimated following Hamilton (1994, page 692).

Table 10 reproduces Table 8 using stochastic switches. The only difference is that the preferred model for premium quality does not include $\Delta \hat{\varepsilon}_{t-9}$ as a regressor. ${ }^{8}$ All coefficients on the error correction terms are negative and significant. The magnitude of these coefficients is roughly in the range -0.5 to -0.2 . Further, coefficients on lagged changes in mark-up on costs are always positive in the range 0.05 to 0.15 and significant in the $L$-regime, while insignificant in the $H$-regime. All these results are very similar to the results obtained for the SETAR model. The estimated parameters for idiosyncratic volatility show that volatility unexplained by the model is at least twice as high in the $H$-regime than in the $L$-regime. ${ }^{9}$ This suggests an alternative interpretation of the separation between regimes; the $L$-regime is characterized by smaller and less volatile shocks while the $H$-regime is characterized by larger and more volatile shocks. 
Next, we present the results for the Wald tests of equal speeds of adjustment towards long-run equilibrium in the two regimes, i.e. $H_{0}: \gamma_{0}^{(L)}=\gamma_{0}^{(H)}$. None of the Wald tests suggest statistically different speeds of adjustment in the two regimes at the $95 \%$ level. The p-values are 0.1393 (regular), 0.0508 (midgrade) and 0.0660 (premium). However, it should be noted that for midgrade and premium qualities the test statistics are only marginally insignificant. These results are similar to the results obtained for the SETAR model for which no asymmetries where detected for regular and midgrade qualities (only for premium quality there is some evidence of asymmetry).

To summarize, the overall picture does not change when switches between regimes are stochastic instead of deterministic. We still find two regimes in the data, meaning that the adjustment process is non-linear. Further, parameter estimates are almost always of the same sign and magnitude and the same parameters are usually statistically significant. This additional evidence strengthens our case for the presence of non-linearities in the adjustment of mark-up on costs to their long run levels. This evidence also supports the conclusion obtained using the deterministic framework - there is no need for government intervention in the New York petroleum market. 


\section{Notes}

${ }^{1}$ The aggregation of prices can take the form of: geographical markets (e.g. on a national level), frequency (e.g. monthly averages); types of products (e.g. aggregated unleaded petrol); market stage (e.g. from refiners directly to filling stations); and, cost items (e.g. prices including taxes or net of country-wide taxation rate).

${ }^{2}$ The expectation is that suppliers are likely to squeeze retailers to reduce their (retailers) profit margins.

${ }^{3}$ Regular, Midgrade and Premium petroleum have the octane rating of (respectively) greater than 85 and less than or equal to 90 , greater than 88 and less than or equal to 90 , and greater than 90 .

${ }^{4}$ Critical values from Banarjee (1993, Table 4.2, p. 103).

${ }^{5}$ The p-values are interpolated from Phillips \& Ouliaris (1990, Table Ia and Ib, p. 189).

${ }^{6}$ Changes in the values of $m$ do not affect the results.

${ }^{7}$ In the model $r^{(j)}$ stands for threshold, $d^{(j)}$ is the delay parameter, $F_{12}$ is the linearity test advocated in Hansen (1996), calculated using 2000 replications. To avoid trivial results, in the grid the top and bottom $15 \%$ threshold values are disregarded.

${ }^{8}$ When the $t-9$ lag is included, the only notable difference is that the coefficient for $\Delta \hat{\varepsilon}_{t-3}^{(L)}$ becomes insignificant.

${ }^{9}$ Parameter estimates are not reported but available on request. 


\section{References}

Abdulai, A. (2002), 'Using threshold cointegration to estimate asymmetric price transmission in the swiss pork market', Applied Economics Letters (6), 467-470.

Bachmeier, L. \& Griffin, J. (2003), 'New evidence on asymmetric gasoline price responses', The Review of Economics and Statistics 85(3), 772-776.

Bacon, R. (1991), 'Rockets and feathers: the asymmetric speed of adjustment of UK retail gasoline prices to cost changes', Energy Economics 13(3), 211-218.

Balke, N., Brown, S. P. \& Yücel, M. (1998), 'Crude oil and gasoline prices: an asymmetric relationship?', Economic and Financial Policy Review (Q 1), 2-11.

Banarjee, A. (1993), Co-integration, error correction, and the econometric analysis of nonstationary data, Oxford University Press.

Borenstein, S., Cameron, A. \& Gilbert, R. (1997), 'Do gasoline prices respond asymmetrically to crude oil changes', Quarterly Journal of Economics 112, 305-339.

Competition Bureau (1997), Discontinued inquiries concerning Canada's gasoline industry: Report by Competition Bureau, Gatineau, Quebec.

Duffy-Deno, K. T. (1996), 'Retail price asymmetries in local gasoline markets', Energy Economics (18), 81-92.

Eckert, E. (2002), 'Retail prices cycles and response asymmetry', Canadian Journal of Economics, Vol.35, No.1, 52-777 35(1), 52-77.

Energy Information Agency (1999), 'Price changes in the gasoline market: Are midwestern gasoline prices downward sticky?', US Department of Energy.

Engle, R. \& Granger, C. (1987), 'Cointegration and error correction: Representation estimation and testing', Econometrica 55(2), 251-276. 
Frey, G. \& Manera, M. (2005), Econometric models of asymmetric price transmission, Working Papers 2005.100, Fondazione Eni Enrico Mattei. available at http://ideas.repec.org/p/fem/femwpa/2005.100.html.

General Accounting Office (1993), Energy security and policy: Analysis of the pricing of crude oil and petroleum products: Report by General Accounting Office, Washington, DC.

Geweke, J. (1978), 'Temporal aggregation in the multiple regression model', Econometrica 46, 643-662.

Godby, R., Lintner, A., Stengos, T. \& Wandschneider, B. (2000), 'Testing for asymmetric pricing in the canadian retail gasoline market', Energy Economics (22), 251-276.

Hamilton, J. (1989), 'A new approach to the economic analysis of non-stationary time series and the business cycle', Econometrica 57, 357-384.

Hamilton, J. (1994), Time series analysis, Princeton University Press Princeton, NJ.

Hansen, B. E. (1996), 'Inference when a nuisance parameter is not identified under the null hypothesis', Econometrica 64(2), 413-430.

Hansen, B. E. (1997), 'Inference in tar models', Studies in Nonlinear Dynamics and Econometrics 2, 1-22.

Karrenbrock, J. (1991), 'The behaviour of retail gasoline prices: Symmetric or not?', Federal Reserve Bank of St. Louis pp. 19-29.

Maskin, E. \& Tirole, J. (1988), 'A theory of dynamic oligopoly, ii: Price competition, kinked demand curves, and edgeworth cycles', Econometrica 56(3), 571-99.

Monopolies and Mergers Commission (1990), The Supply of Petrol: Monopolies and Mergers Commission Report, HMSO, London.

Noel, M. (2007), 'Edgeworth price cycles, cost-based pricing and sticky pricing in retail gasoline markets', Job market paper. Cambridge, Massachusetts: Massachusetts Institute of Technology 89(2), 324 . 
Office of Fair Trading (1998), Competition in the Supply of Petrol: Office of Fair Trading Report, OFT, London.

Phillips, P. C. B. \& Ouliaris, S. (1990), 'Asymptotic properties of residual based tests for cointegration', Econometrica 58(1), 165-93.

Radchenko, S. (2005), 'Oil price volatility and the asymmetric response of gasoline prices to oil price increases and decreases', Energy Economics 27(5), 708-730.

Radchenko, S. \& Tsurumi, H. (2005), 'Limited information bayesian analysis of a simultaneous equation with an autocorrelated error term and its application to the us gasoline market', Journal of Econometrics 133, 31-49.

Reilly, B. \& Witt, R. (1998), 'Petrol price asymmetries revisited', Energy Economics (20), 297-308.

RFA (2006), Changes in gasoline and the automobile service technician, Report, Renewable Fuels Association. available at www.ethanolrfa.org/objects/ pdf/AboutRFA/Gasoline.pdf.

Shin, D. (1992), Do Product Prices Respond Symmetrically to Changes in Crude Prices?, American Petroleum Institute.

Tong, H. (1978), 'On a threshold model', Pattern Recognition and Signal Processing pp. 101141.

Tong, H. \& Lim, K. S. (1980), 'Threshold autoregression, limit cycles and cyclical data', Journal of the Royal Statistical Society. Series B (Methodological) 42(3), 245-292.

Tsay, R. (1998), 'Testing and modeling multivariate threshold models', Journal of the American Statistical Association 93(443), 1188-1202.

von Cramon-Taubadel, S. \& Mayer, J. (2001), 'Asymmetric price transmission: Fact or artefact?', Paper prepared for the 71th EAAE Seminar The food consumer in the early 21st century in Zaragoza, Spain, 19-20 April 2001 pp. 1-15. 
Figure 1: Examples of symmetric (lower left panel) and asymmetric (lower right panel) price transmission
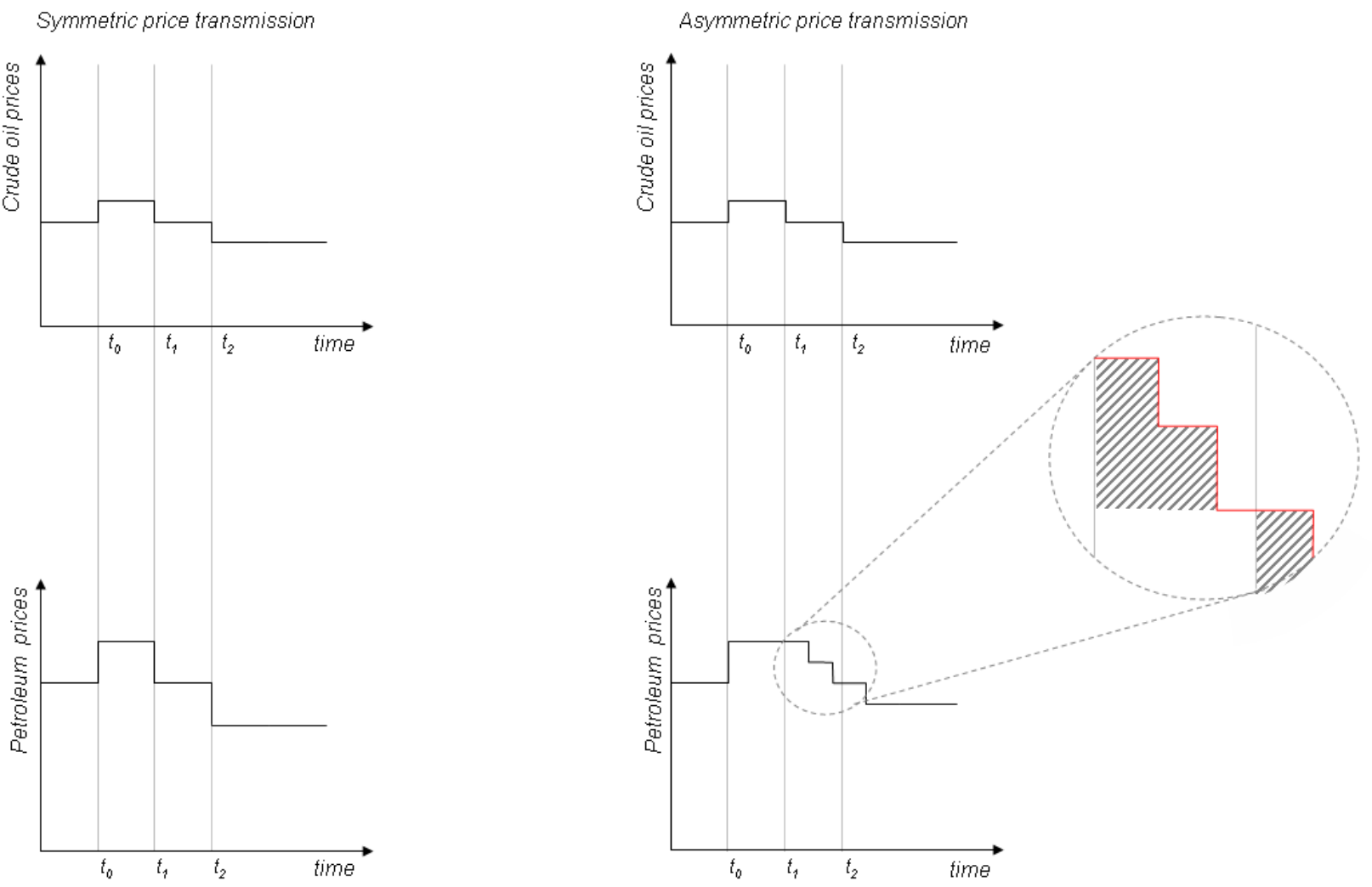
Figure 2: Series analyzed.

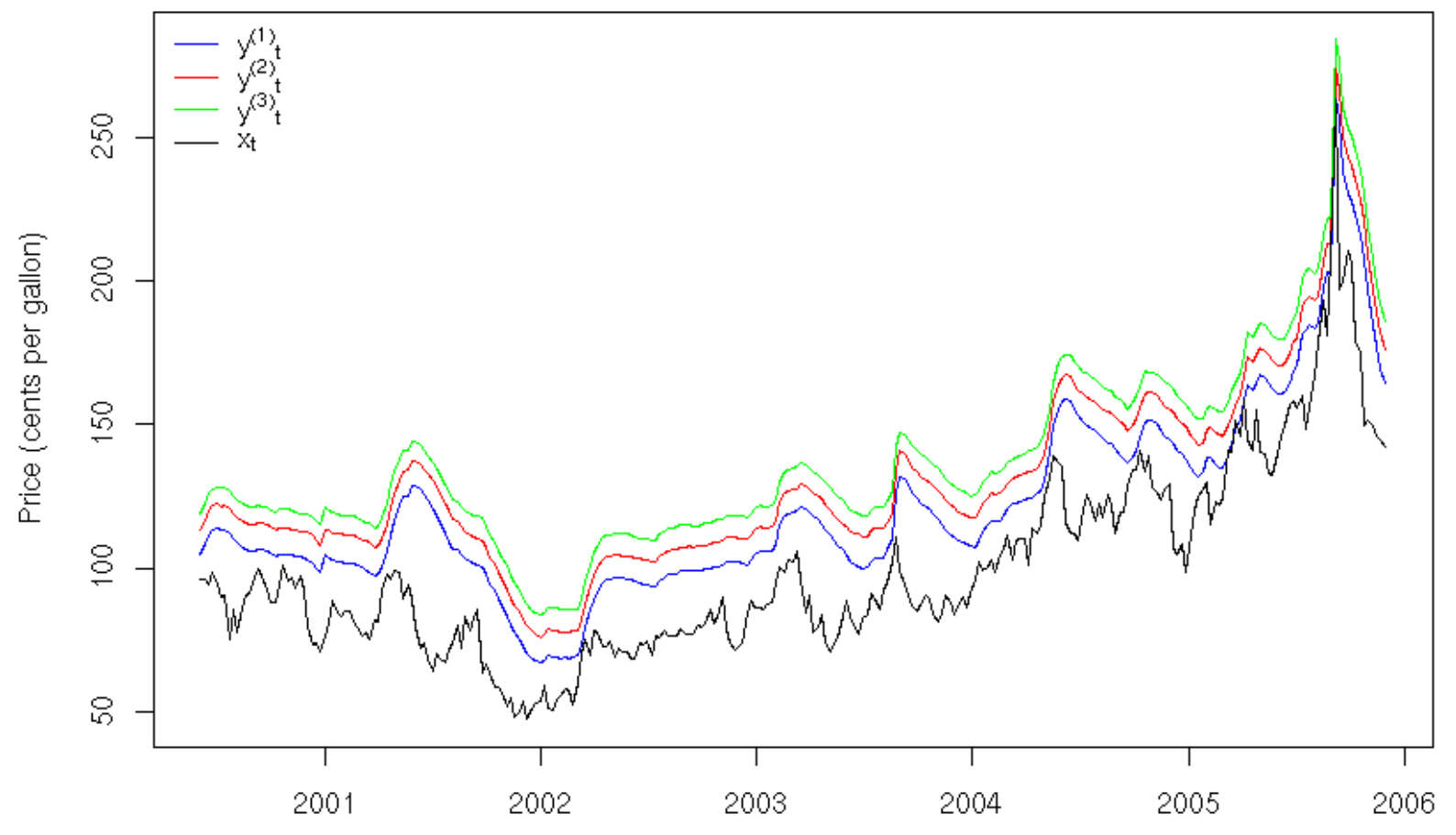


Figure 3: Share of upstream prices in final product price.

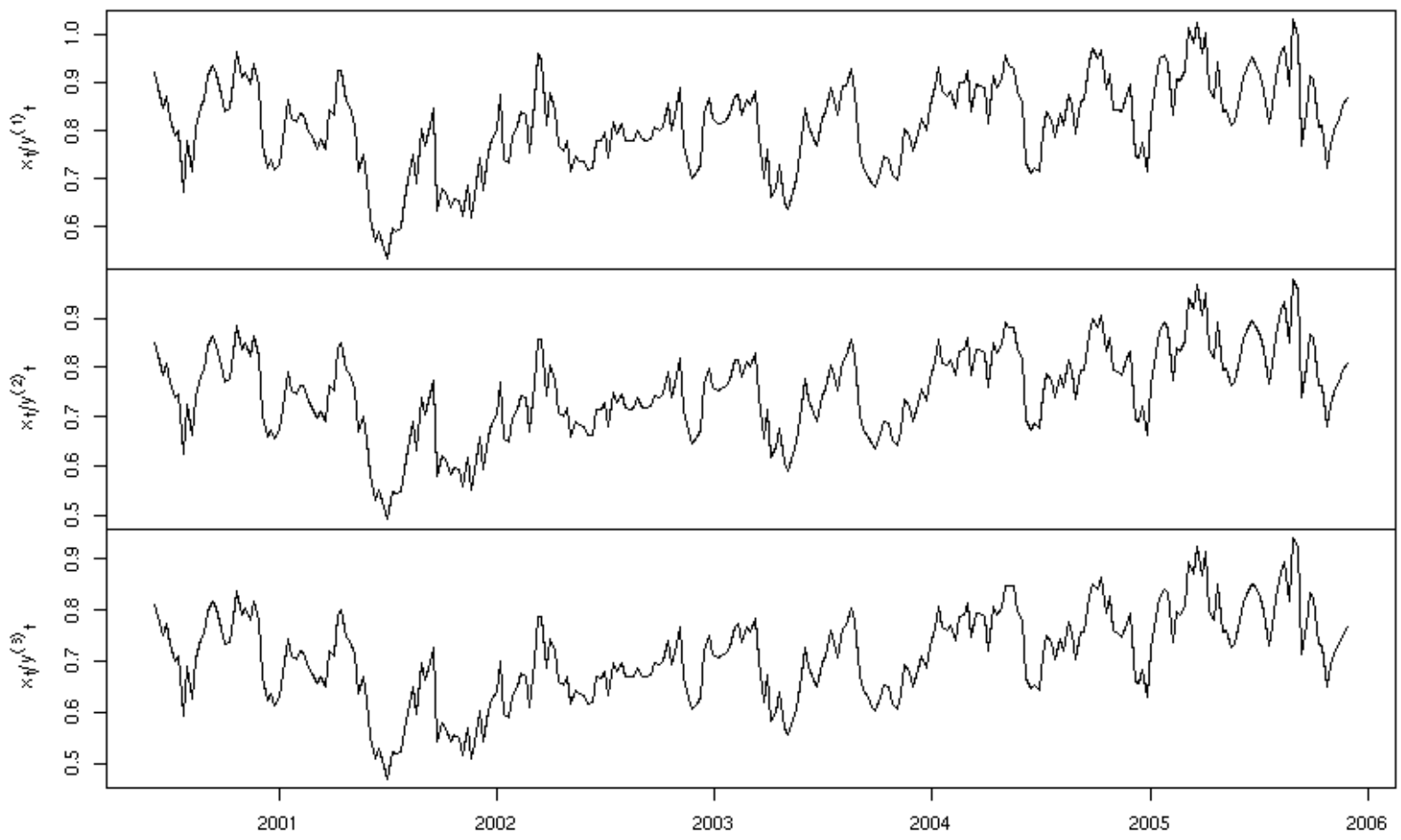


Figure 4: Mark-ups on products.

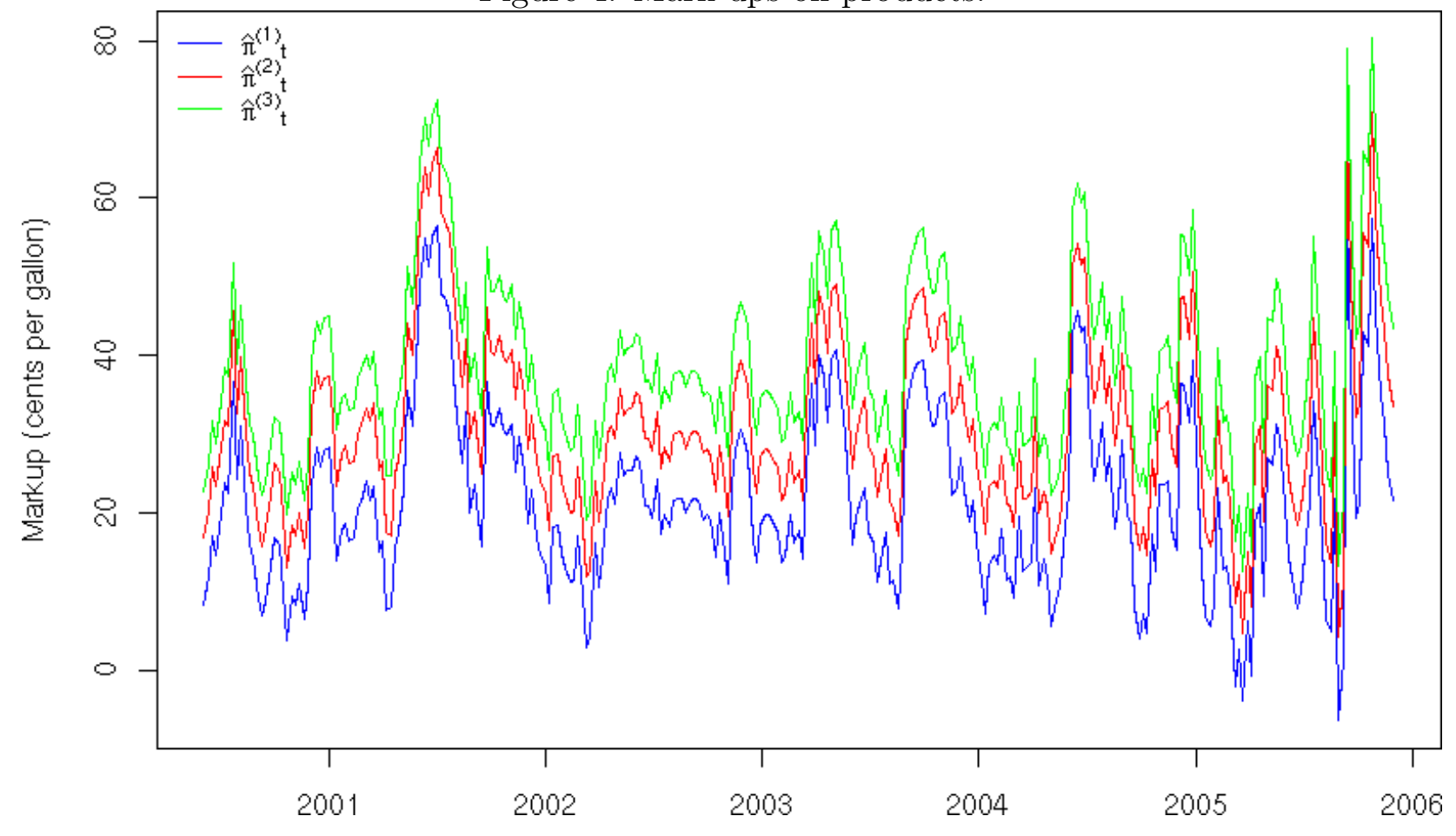


Figure 5: Regime behavior - adjustment towards the long run equilibrium (left panel $\Delta \hat{\pi}_{t}^{(j)}$, right panel $\hat{\pi}_{t}^{(j)}$.)
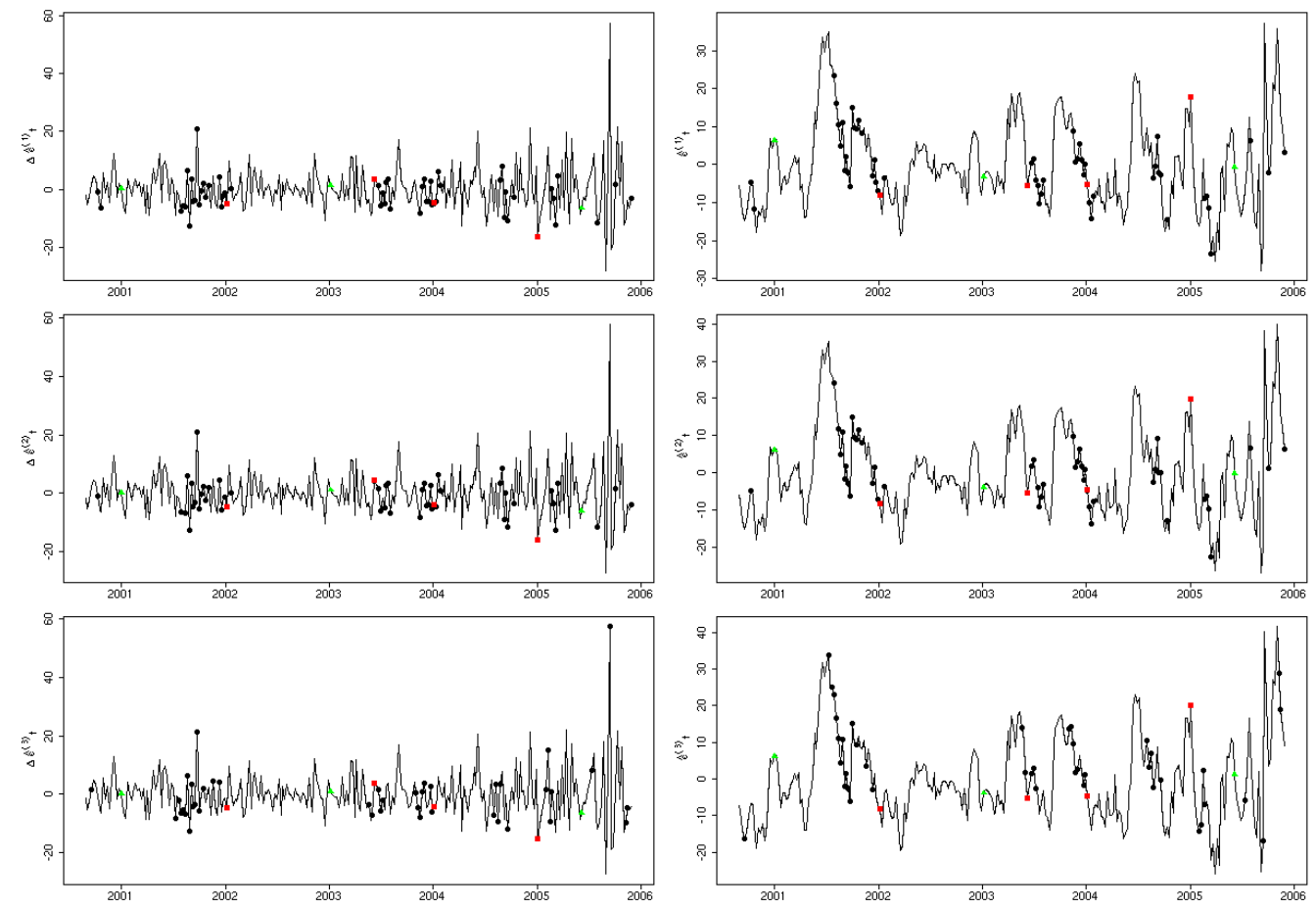
Table 1: Granger Causality tests for series analyzed.

\begin{tabular}{lrr}
\hline & F-statistic & p-value \\
\hline$y_{t}^{(1)} \rightarrow x_{t}$ & 0.02 & 0.89 \\
$y_{t}^{(2)} \rightarrow x_{t}$ & 0.00 & 0.99 \\
$y_{t}^{(3)} \rightarrow x_{t}$ & 0.01 & 0.93 \\
\hline$x_{t} \rightarrow y_{t}^{(1)}$ & 110.06 & 0.00 \\
$x_{t} \rightarrow y_{t}^{(2)}$ & 111.51 & 0.00 \\
$x_{t} \rightarrow y_{t}^{(3)}$ & 110.63 & 0.00 \\
\hline
\end{tabular}


Table 2: ADF tests for series analyzed.

\begin{tabular}{llrrr}
\hline Variable & Estimate & Std.Error & t-stat & p-value \\
\hline$x_{t-1}$ & -0.02 & 0.02 & -1.64 & 0.10 \\
$\Delta x_{t-1}$ & -1.16 & 0.06 & -19.35 & 0.01 \\
\hline$y_{t-1}^{(1)}$ & -0.00 & 0.01 & -0.51 & 0.10 \\
$\Delta y_{t-1}^{(1)}$ & -0.80 & 0.06 & -13.30 & 0.01 \\
\hline$y_{t-1}^{(2)}$ & -0.01 & 0.01 & -0.74 & 0.10 \\
$\Delta y_{t-1}^{(2)}$ & -0.80 & 0.06 & -13.27 & 0.01 \\
\hline$y_{t-1}^{(3)}$ & -0.01 & 0.01 & -0.64 & 0.10 \\
$\Delta y_{t-1}^{(3)}$ & -0.63 & 0.09 & -7.09 & 0.01 \\
\hline
\end{tabular}


Table 3: Phillips-Ouliaris tests for the null of no cointegration in the series analyzed.

\begin{tabular}{lcc}
\hline Cointegration Pair & Statistics & P-Value \\
\hline$y_{t}^{(1)}, x_{t}$ & -60.3520 & 0.01 \\
$y_{t}^{(2)}, x_{t}$ & -59.7279 & 0.01 \\
$y_{t}^{(3)}, x_{t}$ & -59.7693 & 0.01 \\
\hline
\end{tabular}


Table 4: OLS estimation of the series analyzed.

\begin{tabular}{lrrrr}
\hline & Estimate & Std. Error & $\mathrm{t}$ value & $\operatorname{Pr}(>|\mathrm{t}|)$ \\
\hline$\beta_{0}^{(1)}$ & 27.8661 & 2.0896 & 13.34 & 0.0000 \\
$\beta_{1}^{(1)}$ & 0.9372 & 0.0199 & 47.03 & 0.0000 \\
\hline$\beta_{0}^{(2)}$ & 35.8471 & 2.1328 & 16.81 & 0.0000 \\
$\beta_{1}^{(2)}$ & 0.9520 & 0.0203 & 46.80 & 0.0000 \\
\hline$\beta_{0}^{(3)}$ & 41.7649 & 2.1690 & 19.26 & 0.0000 \\
$\beta_{1}^{(3)}$ & 0.9687 & 0.0207 & 46.83 & 0.0000 \\
\hline
\end{tabular}


Table 5: Estimation of Long-run level of mark-up proxies $\hat{\pi}_{t}^{(j)}$.

\begin{tabular}{lrrrr}
\hline & Estimate & Std. Error & t value & $\operatorname{Pr}(>|\mathrm{t}|)$ \\
\hline$\alpha^{(1)}$ & 21.6146 & 0.6698 & 32.27 & 0.0000 \\
$\alpha^{(2)}$ & 31.0668 & 0.6786 & 45.78 & 0.0000 \\
$\alpha^{(3)}$ & 38.6502 & 0.6861 & 56.33 & 0.0000 \\
\hline
\end{tabular}


Table 6: Estimation of linear model of adjustment for $\hat{\pi}_{t}^{(j)}$.

\begin{tabular}{crrrr}
\hline Variable & Estimate & Std. Error & $\mathrm{t}$ value & $\operatorname{Pr}(>|\mathrm{t}|)$ \\
\hline$\hat{\epsilon}_{t-1}^{(1)}$ & -0.2455 & 0.0386 & -6.36 & 0.0000 \\
$\Delta \hat{\epsilon}_{t-3}^{(1)}$ & 0.1469 & 0.0567 & 2.59 & 0.0101 \\
\hline$\hat{\epsilon}_{t-1}^{(2)}$ & -0.2404 & 0.0383 & -6.28 & 0.0000 \\
$\Delta \hat{\epsilon}_{t-3}^{(2)}$ & 0.1437 & 0.0569 & 2.53 & 0.0121 \\
\hline$\hat{\epsilon}_{t-1}^{(3)}$ & -0.2410 & 0.0380 & -6.34 & 0.0000 \\
$\Delta \hat{\epsilon}_{t-3}^{(3)}$ & 0.1498 & 0.0570 & 2.63 & 0.0090 \\
$\Delta \hat{\epsilon}_{t-9}^{(3)}$ & 0.0837 & 0.0573 & 1.46 & 0.1454 \\
\hline
\end{tabular}


Table 7: Overview of SETAR models - structure of models

\begin{tabular}{lccc}
\hline Variable & $d^{(j)}$ & $r^{(j)}$ & $F_{12}$ \\
\hline$\Delta \hat{\epsilon}_{t}^{(1)}$ & 11 & 8.902501 & $16.59906^{*}$ \\
$\Delta \hat{\epsilon}_{t}^{(2)}$ & 11 & 9.322401 & $19.34938^{*}$ \\
$\Delta \hat{\epsilon}_{t}^{(3)}$ & 8 & 10.61444 & $52.24798^{*}$ \\
\hline
\end{tabular}


Table 8: Estimation of non-linear model of adjustment for $\hat{\pi}_{t}^{(j)}$.

\begin{tabular}{rrrrr}
\hline Variable & Estimate & Std. Error & t value & $\operatorname{Pr}(>|\mathrm{t}|)$ \\
\hline$\hat{\epsilon}_{t-1}^{(1, L)}$ & -0.2587 & 0.0414 & -6.25 & 0.0000 \\
$\hat{\epsilon}_{t-1}^{(1, H)}$ & -0.1814 & 0.1147 & -1.58 & 0.1147 \\
$\Delta \hat{\epsilon}_{t-3}^{(1, L)}$ & 0.1879 & 0.0701 & 2.68 & 0.0078 \\
$\Delta \hat{\epsilon}_{t-3}^{(1, H)}$ & 0.0752 & 0.0975 & 0.77 & 0.4408 \\
\hline$\hat{\epsilon}_{t-1}^{(2, L)}$ & -0.2441 & 0.0405 & -6.02 & 0.0000 \\
$\hat{\epsilon}_{t-1}^{(2, H)}$ & -0.2488 & 0.1258 & -1.98 & 0.0490 \\
$\Delta \hat{\epsilon}_{t-3}^{(2, L)}$ & 0.1816 & 0.0701 & 2.59 & 0.0102 \\
$\Delta \hat{\epsilon}_{t-3}^{(2, H)}$ & 0.0688 & 0.0982 & 0.70 & 0.4842 \\
\hline$\hat{\epsilon}_{t-1}^{(3, L)}$ & -0.1832 & 0.0410 & -4.47 & 0.0000 \\
$\hat{\epsilon}_{t-1}^{(3, H)}$ & -0.5111 & 0.0947 & -5.40 & 0.0000 \\
$\Delta \hat{\epsilon}_{t-3}^{(3, L)}$ & 0.0939 & 0.0604 & 1.55 & 0.1214 \\
$\Delta \hat{\epsilon}_{t-3}^{(3, H)}$ & 0.4183 & 0.1608 & 2.60 & 0.0098 \\
$\Delta \hat{\epsilon}_{t-9}^{(3, L)}$ & 0.0774 & 0.0697 & 1.11 & 0.2683 \\
$\Delta \hat{\epsilon}_{t-9}^{(3, H)}$ & 0.1329 & 0.1042 & 1.27 & 0.2035 \\
\hline
\end{tabular}


Table 9: Changes in taxation and clustering of observations in regime $H$.

\begin{tabular}{lcc}
\hline $\mathrm{k}$ & Variable & In regime $H$ \\
\hline \pm 4 & $\Delta \hat{\epsilon}_{t}^{(1)}$ & $33 \%$ \\
\pm 4 & $\Delta \hat{\epsilon}_{t}^{(2)}$ & $31 \%$ \\
\pm 4 & $\Delta \hat{\epsilon}_{t}^{(3)}$ & $24 \%$ \\
\hline \pm 6 & $\Delta \hat{\epsilon}_{t}^{(1)}$ & $41 \%$ \\
\pm 6 & $\Delta \hat{\epsilon}_{t}^{(2)}$ & $39 \%$ \\
\pm 6 & $\Delta \hat{\epsilon}_{t}^{(3)}$ & $33 \%$ \\
\hline \pm 8 & $\Delta \hat{\epsilon}_{t}^{(1)}$ & $50 \%$ \\
\pm 8 & $\Delta \hat{\epsilon}_{t}^{(2)}$ & $49 \%$ \\
\pm 8 & $\Delta \hat{\epsilon}_{t}^{(3)}$ & $43 \%$ \\
\hline
\end{tabular}


Table 10: Table 8 Reproduced with Stochastic Switches

\begin{tabular}{rrrrr}
\hline Variable & Estimate & Std. Error & $t$-value & $p$-value \\
\hline$\hat{\varepsilon}_{t-1}^{(1, L)}$ & -0.2053 & 0.0368 & -5.57 & 0.0000 \\
$\hat{\varepsilon}_{t-1}^{(1, H)}$ & -0.5375 & 0.2232 & -2.41 & 0.0161 \\
$\Delta \hat{\varepsilon}_{t-3}^{(1, L)}$ & 0.1387 & 0.0686 & 2.02 & 0.0433 \\
$\Delta \hat{\varepsilon}_{t-3}^{(1, H)}$ & 0.0726 & 0.1466 & 0.50 & 0.6205 \\
\hline$\hat{\varepsilon}_{t-1}^{(2, L)}$ & -0.1752 & 0.0379 & -4.62 & 0.0000 \\
$\hat{\varepsilon}_{t-1}^{(2, H)}$ & -0.3871 & 0.1083 & -3.57 & 0.0000 \\
$\Delta \hat{\varepsilon}_{t-3}^{(2, L)}$ & 0.1412 & 0.0652 & 2.16 & 0.0304 \\
$\Delta \hat{\varepsilon}_{t-3}^{(2, H)}$ & 0.1291 & 0.1280 & 1.01 & 0.3134 \\
\hline$\hat{\varepsilon}_{t-1}^{(3, L)}$ & -0.1787 & 0.0413 & -4.33 & 0.0000 \\
$\hat{\varepsilon}_{t-1}^{(3, H)}$ & -0.3673 & 0.1032 & -3.56 & 0.0004 \\
$\Delta \hat{\varepsilon}_{t-3}^{(3, L)}$ & 0.1396 & 0.0662 & 2.11 & 0.0350 \\
$\Delta \hat{\varepsilon}_{t-3}^{(3, H)}$ & 0.1319 & 0.1308 & 1.01 & 0.3130 \\
\hline
\end{tabular}

